\title{
An Exploratory Study of the Digital Competences of Italian Accountants: Some Preliminary Results
}

\author{
Rosalinda Santonastaso ${ }^{1}$ \& Riccardo Macchioni ${ }^{1}$ \\ ${ }^{1}$ Department of Economics, University of Campania "Luigi Vanvitelli”, Capua (CE), Italy \\ Correspondence: Rosalinda Santonastaso, Department of Economics, University of Campania "Luigi Vanvitelli”, \\ Capua, Italy. E-mail: rosalinda.santonastaso@unicampania.it
}

Received: October 24, 2021

Accepted: November 27, 2021

Online Published: December 31, 2021

doi:10.5539/ijbm.v17n2p13

URL: https://doi.org/10.5539/ijbm.v17n2p13

\begin{abstract}
Purpose - This paper examines the current digital competences of Italian accountants and to what extent these competences are evident in their competence profiles.
\end{abstract}

Methodology - In this study, 6,442 profiles of accountants, extracted from the professional social network LinkedIn, were analysed using the technique for the analysis of textual data.

Findings - The results of the study reveal that the male users expose more often in their professional profiles the possession of information technology skills than female accountants. Moreover, the results highlight a limited development of data analytics skills, which are reported in only $13 \%$ of the LinkedIn profiles analysed. Furthermore, the findings also show that there is a gap between the digital competences held by accountants who belong to different geographical areas. The accountants living in northern Italy, in fact, report more digital competences in their LinkedIn profiles than those living in central and southern Italy.

Originality - This study stimulates the ongoing debate on the competence's changes of the accountants in the digital technology era.

Keywords: accountants, digital competences, professional social network, text analysis

\section{Introduction}

In the current economic context, the digital innovation is a factor that stimulates the change (Wessels, 2005). In particular, the use of artificial intelligence and the analysis of big data leads, on the one hand, to a transformation of work practices with the creation of new professions, such as artificial intelligence specialist and big data specialist and, on the other hand, an increased risk of computerization that extends to a wide range of jobs (Ford, 2015; Brynjolfsson \& Mcafee, 2014) (Note 1). The demand for digital competences for the professions can be seen not only in the specialized technological fields, but also in the more traditional ones, where a lack of digital skills is also added to a general inadequacy of basic skills (Berger \& Frey, 2016).

In the accounting field, for instance, there is an increasing risk that the disruptive force of digital technologies will lead to a transformation of the profession. Frey and Osborne (2017) predict a 94\% likelihood that the accounting activities, for the mechanical and routine part, will end up being automated. In particular, the traditional activities such as the bookkeeping and tax returns will be recognized as less important. On the contrary, the assistance to the customer in business consulting area will become the core business of the future professionals. The influence of digital technologies in the workplace will not be immediate. Nevertheless, the current "entry-level" jobs that require low cognitive abilities may disappear quickly. Manyika et al. (2017) estimate that at least $50 \%$ of the activities carried out by accountants will be automatable through the technologies currently available, while a further $15 \%$ will become so in the near future.

The advent of technology, however, also creates interesting opportunities for the accounting profession, which can rely on a greater variety of data and analytical software to expand the possibility of solving complex problems (Schneider, Dai, Janvrin, Ajayi, \& Raschke, 2015). In a period of rapid change, the support that accountants could provide to companies - through the offer of a wide range of services such as big data analysis or support with cloud computing - becomes even more valuable (Riddell, 2016) (Note 2). Therefore, the companies will expect their consultants to provide innovative services with high added value and an ongoing support in both the web marketing sector and the use of technological systems. 
The monitoring of technological development of EU Member States has also become one of the main points of discussion of the European Commission. However, Italy is not among the most advanced digital economies in the EU (European Commission, 2020). For this reason, it is interesting to examine the level of the digital competences in the Italian accounting profession.

Despite the relevance of this question, no attempts have been made to study the level of the current competences of accountants. In responding to this research gap, this paper aims to observe the possession of digital competences (such as information technology skills and data analytics skills) by accountants, to verify whether and to what extent these competences are evident in their competence profiles, based on a complete set of 6,442 published profiles LinkedIn (http://www.linkedin.com), the largest professional social network in the world (Bastian et al., 2014). Consequently, we use the text analysis, a technique for the analysis of textual data, in order to analyse the information contained in the 6,442 LinkedIn profiles.

The remainder of the paper is structured as follows. The second section presents a review of the literature on digital competences in accounting profession. The third section, which deals with the methodology, justifies the use of LinkedIn profiles as a data source and then describes the processes of extraction, preparation and processing data. The empirical results of the study are included in the fourth section, while the final discussion and the study's limitations are summarized in the fifth section.

\section{Literature Review}

The rapid development of communication networks, databases and information systems requires the presence of professionals who possess an interdisciplinary knowledge in various areas, such as Enterprise Resource Planning (ERP), extensible Business Reporting Language (XBRL), Business Intelligence (BI) and Business Analytics (BA) (Appelbaum, Kogan, \& Vasarhelyi, 2017) (Note 3). In particular, the development of sophisticated machine learning algorithms and the elaboration of the natural language contributes to make the hypothesis of an automation of the accounting tasks more concrete (Note 4).

Consequently, accountants need to develop new and diversified competences by replacing traditional tasks with activities that are difficult to automate. In addition, in a data-driven economy, they will also need to gain a better understanding of statistics and complex rules to implement in-depth analyses of the business environment. Moreover, accountants will have to develop new competences to adapt quickly to the different roles and tasks that technological progress will bring out (R. Susskind \& D. Susskind, 2015). All this will contribute to the development of a mentality and an attitude that will allow professionals to exploit the opportunities offered by digital innovation. Moreover, the demand for digital competences seems to play an increasingly important role in all professional profiles, even those not typically related to the world of information and communication technology (ICT).

Therefore, in a world even more globalized and pervaded by technology, there will be not only the birth of new professional figures (typically associated to technology industries) but also the redefinition of established professions, through the introduction of new competences. Therefore, professionals will only be able to evolve their professionalism in the digital age by adopting an attitude of openness towards the change taking place.

In literature, a difference can be discerned between the concepts of "competence", "skill" and "knowledge". Boyatzis (1982) defines competence as an intrinsic individual characteristic which is causally associated to effective or superior performance in a work activity and it is measurable on the basis of a predetermined criterion. In the competences model of Lyle and Signe Spencer (1993), knowledge and skill represent the surface characteristics, visible and easier to develop. In particular, knowledge corresponds to "knowing" because it is likely that someone only knows how to do something (Ahmed, 2003). Skills, instead, express "what you can do". They represent those specific skills that people need to do a job well (Stone, Arunachalam, \& Chandler, 1996). However, the definitions of above concepts, which are the subject of many debates, do not seem to be universally accepted (Georgieva, 2019). In this regard, it is important to clarify that the terms "competence", "skill" and "knowledge" will be used without distinction in this paper.

The sudden change in the methods through which the stakeholders collect, store and process data, makes it necessary to acquire information technology skills (IT) to perform accounting and financial operations. In detail, the accountant must have a background in computer science, mathematical programming and database design (Kaye \& Nicholson, 1992). The most important IT skills is the knowledge and good use of spreadsheets, followed by the ability to use operating systems and software for accounting and word processing (Heagy \& Gallum, 1994). In particular, accountants should be able, in their daily work, to communicate with the computer by uploading and transferring files and using applications such as the Office package (Larres \& Oyeelere, 1999). Indeed, Carnaghan (2004) defines IT skills as the qualities that are expressed through the implementation of activities such as the 
creation of a spreadsheet and a database for a particular purpose, or the use of information software. Bassellier, Benbasat and Reich (2003) distinguish digital skills in knowledge and experience. The former refers to the specific knowledge that the professional possesses, while the digital experiences concern the technical knowledge that individual acquires from interaction with technology. Wessels (2005) identifies, through a review of scientific and professional literature, a series of IT skills which are considered essential for the accounting profession. They include the ability to understand the use of data warehousing, data mining techniques, and antivirus software that protect computer systems from infection (Note 5).

However, digital competences, once acquired, must be continuously updated through a process that leads to the achievement of increasingly advanced competences (da Silva, Tommasetti, Gomes, \& da Silva Macedo, 2020). For example, the data analytics skills, also referred to as big data analytics, represent a broad field that includes a multitude of similar concepts, often used in an alternative way, such as business analytics, real-time analytics, predictive analytics and business intelligence (Chen, Chiang, \& Storey, 2012). In detail, data analytics skills include advanced technologies for storing, managing, analysing and displaying huge amounts of data from various sources (Jordan, 2013). They are also based on statistical data mining techniques that, through the extraction, processing and transformation of information from big data, identify new models and interrelations between variables (Chen et al., 2012). This will enable professionals to improve their risk analysis and management to offer their customers high value-added services (Aldredge, Rogers, \& Smith, 2020).

The role of accountants in the field of digital technologies has been the subject of several scientific publications. Richins, Stapleton, Stratopoulos and Wong (2017) argue that technological progress could transform the functions of the accountant with the exception of some activities that are not easily automated. Accordingly, the Authors suggest that professionals should primarily acquire the skills needed to use and interpret big data by integrating unstructured data with structured data. Bhimani and Willcocks (2014) also state that the accounting activities will undergo substantial changes. Therefore, it is important that professionals become aware that success depends on their ability to embrace technological developments. They should apply a "digital lens" to activities such as the accounting and billing management and the social media monitoring (Colquhoun, 2015). The simplifying certain activities such as tax returns and payment of invoices, will allow accountants to focus more on higher value-added activities for customers (Riddell, 2016).

However, the predominant use of traditional, expensive and inefficient systems developed 20-30 years ago and the reluctance to change accounting practices exposes professionals to the risk of losing customers, who are attracted to those who, on the contrary, have adapted to recent technological developments (Braine, 2016). Warren, Moffitt and Byrnes (2015), in fact, argue that the rise of big data offers sufficient opportunities such as the ability to improve the valuation processes of assets whose value is difficult to determine. Zhyvets (2018) also points out that the advent of digital technologies has significantly increased the level of quality of work carried out by accountants which have the possibility to implement more in-depth economic analyses and to prepare business information with greater speed.

Damasiotis, Trivellas, Santouridis, Nikolopoulos and Tsifora (2015), on the other hand, believe that skills evolve over time, along with other skills, also not digital, which are essential for the performance of different activities. A similar vision is shared by Maisurah, Bahador and Haider (2012) that underline the importance of taking into account the complementary skills to the IT as organizational, conceptual and social. The latter strengthen digital skills and facilitate the professional in carrying out his work.

However, the timeliness in the transmission data flows and easy access to databases, could compromise confidentiality by increasing the risk of fraud (Jordan, 1999). The risk of computer threats to the accounting profession should therefore also be taken into account. The rise of technology and automation is, in fact, a doubleedged weapon that will lead to greater exposure to cyber-attacks (Bullock, 2017). The accounting profession must therefore ensure the protection of sensitive data through the use of reliable and secure IT systems which are capable of preventing direct or indirect alteration of information and the abusive access to data by unauthorized users (Pan \& Seow, 2016).

The issue of digital training is also relevant for international professional bodies. Professional accounting bodies are required to adapt the standards and competence requirements of their members to ensure that accountants are able to take full advantage of the challenges and opportunities generated by technological progress (IFAC Education Committee, 2003). The International Federation of Accountants (IFAC) identifies a vocational training programme which pays particular attention to the ability to use information technology at work and the possession of one or more professional qualifications such as the expert or developer of computer systems. The digital skills of accountants are directly related to their functions, which, in turn, are determined by their position. Indeed, the 
approach adopted by the IFAC is to distinguish between different technical skills in relation to the type of professional qualifications possessed, favoring the strengthening of both those "simpler" such as the use of Excel and the more "complex" ones such as big data management (IFAC, 2017). The American Accounting Association (AAA) promotes big data conferences and webinars that strengthen collaboration between academics and accountants. Professional accounting bodies such as the Chartered Institute of Management Accountants (CIMA), the Institute of Management Accountants (IMA), the Association of Chartered Certified Accountants (ACCA) and the Chartered Accountants Australia and New Zealand (CA ANZ) play a key role in the dissemination of new practices and technologies. They highlight the need to develop a range of skills related to both the mathematicalstatistical field to produce exploratory hypotheses from available data, and the programming and modeling of data to generate added value from the information analysed.

On the basis of the literature review described above, our research aims to observe the possession of digital competences by accountants. Therefore, the research question address in this study is:

$\mathrm{RQ}_{1}$. What digital competences are currently held by accountants and to what extent do these digital competences appear in their professional profiles?

\section{Methodology}

The purpose of the study is exploratory and descriptive. The competences held by accountants are identified through the analysis of profiles users of the professional social network LinkedIn, which is a valid source for a number of reasons.

Firstly, the analysis of the professional competences of accountants would require the collection of a large number of individual information that is not easy to find. Secondly, the information available from a LinkedIn profile, such as educational background, job experience and skills, is similar to the data contained in a traditional Curriculum Vitae (CV) (Oesterreich \& Teuteberg, 2019; Gorbacheva, Stein, Schmiedel, \& Müller, 2016). Therefore, the difficulty of gathering a large number of CVs, for privacy related issues, makes the use of professional social networks (such as LinkedIn) an option that facilitates the accessibility and availability of data. LinkedIn platform gives to its members the opportunity to create and share their professional identity in order to search for new jobs and maintain professional contacts, while companies have the opportunity to recruit jobseekers (Sievers, Wodzicki, Aberle, Keckeisen, \& Cress, 2015). In recent years, the use of social networks has been an integral part of the recruitment strategy for some companies (Bonsón \& Bednárová, 2013). More specifically, LinkedIn is considered the largest professional network in the world, with over 660 million members, active in over 200 countries and territories. It represents one of the fastest growing social communities and it is one of the essential online tools for professionals looking for new job challenges (Hutchinson, 2020; Statista, 2020a).

Previous studies have already relied on professional social networks as a source of data for analysing professional competences. Oesterreich and Teuteberg (2019) examine, using a text analytics approach, a set of 2,331 German Accountants management profiles extracted from XING, a leading social network in the DACH region that includes Germany, Austria and Switzerland. The research aims to investigate the role of business analytics and IT skills in the profession. In the Gorbacheva et al. study (2016), however, the analysis of the skills held by business process management professionals (BPM) was carried out using a Latent Semantic Analysis (LSA) text mining approach on data collected from LinkedIn profiles. While Lohmann and Zur Muehlen (2015) perform an analysis of the content of the LinkedIn profiles of BPM professionals in order to compare the set of skills reported in the professional social network with the skills required in the job advertisements.

\subsection{Data Collection}

In order to collect the highest number of LinkedIn profiles, a premium account has been used that allows you to return up to 500 results per search query. The search query formulated contains the term "Commercialista" with including bookkeepers, tax consultants, fiscal consultants, management consultants and auditors. In addition, in order to analyse some factors, such as personal connections and the country of affiliation, the following search filters have been applied:

a) The social network LinkedIn allows different members to connect with each other, through the creation of subcommunity of friends. As a result, in order to manage personal bias on the selected profiles, the contacts belonging to the 1 st and 2 nd circles of connections (direct contacts and contact contacts) have been excluded from the search. Therefore, only the profiles belonging to the 3rd circle of connection and those that do not belong to a specific connection circle have been selected.

b) The search for individual profiles was carried out by selecting Italy as the country of origin. In particular, in order to conduct an analysis that takes into account the territorial dynamics, as well as national, the 
extraction of profiles was carried out by region.

The combination of different search filters returned a total number of LinkedIn profiles which was initially equal to 23,857 units. Due to the private browsing of some users, it was only possible to extract a total number of 13,759 profiles. The data collection process covered a period of five months (from February to June 2020) due to the daily restrictions imposed on the extraction of all necessary information.

\subsection{Data Preparation}

The process of preparing the data has been set out in two steps to ensure the cleanliness of the information collected in a disorderly manner.

i. Data cleaning: At this stage, the profiles clearly "fake" and with missing data have been deleted to ensure the inclusion in the subsequent analysis of only meaningful and good quality information. In detail, 40 fake profiles with fake names such as "Arga", "Efrem", "Bindikuo" or "Errol" have been identified. In addition, a number of 7,277 profiles have been deleted without any content in the "skills" section of the professional social network. At the end of data cleaning, the final sample consists of 6,442 LinkedIn profiles (Tab. 1).

ii. Data integration: This phase involves the integration of individual-level data obtained from the completion of additional procedures. To identify the gender of each LinkedIn profile, it has been observed the first name and the image offered in the profile. Where this procedure proved inadequate, the cases were examined individually. In particular, for each profile without a photo, a search by first and last name has been carried out manually on Google's web engine or on other social networks such as Facebook or Twitter.

Table 1. Phases of constitution of the study sample

\begin{tabular}{ll}
\hline Description & \multicolumn{1}{c}{$N$} \\
\hline Number of extracted member profiles: & 23,857 \\
Number of LinkedIn member with private profile: & 10,098 \\
Number of fake profiles: & 40 \\
Number of profiles without any content in the "skills" section: & 7,277 \\
Total study sample & 6,442 \\
\hline
\end{tabular}

\subsection{Data Analysis}

The information collected is examined using semantic techniques for the analysis of textual data (text analysis).

There is a difference between the structured and unstructured data. Structured data can be classified and categorized according to specific rules and schemes defined in advance by the user. Unstructured data, on the contrary, are not stored in tables and it is difficult to easily identify their contents. The unstructured data, without a pre-defined model, constitute the majority of existing data (Gandomi \& Haider, 2015). Indeed, the extraction of relevant and meaningful information from the images and audio/video recordings of seminars and conferences is a quite complicated process (Crovara, 2009). Therefore, unstructured data must be subjected to coding processes that are traditionally executed manually. However, manual coding, as evidenced in the social sciences, would make the process long and subject to many limitations and biases (Oesterreich \& Teuteberg, 2019).

Furthermore, given the considerable efforts to manually encode the information extracted from 6,442 LinkedIn profiles, a manual encoding process would be completely inappropriate for the purpose of the following research. In detail, the extracted sample, stored in Excel spreadsheets, includes both structured data such as the full name and the number of connections between LinkedIn users, and unstructured data as the competences listed in the section dedicated entirely to the inclusion of skills on the professional social network.

The research method used, therefore, is the text analysis, which allows you to extract insights, with both informative and predictive value, from a large amount of unstructured data, accelerating the encoding process. This method, however, requires knowledge of various statistical techniques that are not immediately available in common statistical software (Welbers, Van Atteveldt, \& Benoit, 2017). The only statistical software that can facilitate the process of analysis of textual data is " $R$ ". This open-source programming environment is equipped with a number of text analysis packages, provided and managed by a large user community. In particular, about 50 packages can be identified that ensure the application of multiple textual analysis techniques, from the simplest to the most advanced (Roberts et al., 2014).

From an operational point of view, the text analysis was carried out following a process consisting of three phases, 


\section{illustrated in Figure 1.}

The first stage of pre-processing data is essential because the data, being unstructured and with a low level of standardization, cannot be directly subjected to statistical processing. Therefore, the profiles extracted from LinkedIn previously stored in a ".csv" format, were imported into R to start the operations of tokenization and normalization. Tokenization allows you to split text data into smaller and more specific text parts, such as individual words or combinations of them. The indicators used for subdivision are white spaces, dots and commas. Normalization, on the other hand, allows you to improve the characteristics of the imported text through the removal of the words considered not of interest that are then removed before the analysis. It acts on non-separator characters to eliminate possible sources of "split" of the data, for example removing differences between upperand lower-case characters. Furthermore, since a word could have different morphological variations due to conjugations of verbs, plural declinations and acronyms, it is necessary to identify the root of each word through the lemmatization technique. The principle behind this practice is that for the aforementioned variations having a similar meaning, it is possible to identify semantic invariants whose meaning does not vary with the bending.

Once these operations have been completed, the second stage of organization and representation of the database has been carried out. Specifically, a "document-term matrix" (DTM) has been constructed in which the rows are represented by the documents (i.e., the profiles of the accountants), the columns by terms (i.e., the competences illustrated in the appropriate section "skills" identifiable on the LinkedIn platform), and the cells by the frequency with which each term recurs in each profile.

The third phase is the data analysis, in which it is possible to proceed, alternatively, according to three approaches: the method of counting and dictionary, supervised machine learning and unsupervised machine learning (Boumans $\&$ Trilling, 2016). These are approaches that adopt a logic that goes from the most deductive to the most inductive. The method of counting and dictionary adopts a deductive logic. In the definition of categories, the researchers use a matrix of categorization composed of concepts, models or hypotheses taken from the existing literature. Subsequently, the collected data will be brought back into the categories included in the matrix. The logic that drives supervised machine learning and unsupervised machine learning methods, on the contrary, is inductive. The algorithms create a general framework from specific observations. More specifically, the categories are defined through a process that breaks down, classifies and synthesizes the content of the textual data. The purpose is not only to combine similar or related observations, but it is also to identify relationships that allow to describe the phenomenon by increasing its understanding and generating new knowledge.

In this paper, the counting and dictionary method is adopted, defining a priori the categories to be analysed. Consequently, the IT skills and data analytics skills are automatically identified through the review of the literature described in the second paragraph. However, regardless of the approach taken, the outcomes resulting from the text analysis process must meet the accuracy and validity requirements (Leopold \& Kindermann, 2002). The technique and the coding rules adopted must be accurate and ensure stability and reproducibility in the analysis process. The latter, based on fixed rules, must be able to produce, over time, evidence without significant distortions, even if repeated by different individuals. The requirement of validity, on the other hand, is closely associated to the clarity with which the different passages that characterized the research are described. It expresses the degree of correspondence between the results of the research and the social phenomenon they describe.

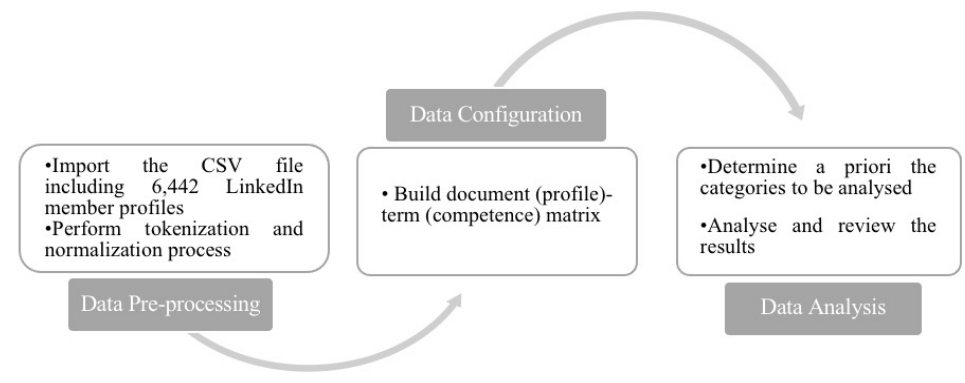

Figure 1. Representation of the three phases in the process of text analysis

\section{Results}

In this section, the results obtained from the empirical analysis of the data are illustrated. In a first step, the LinkedIn 
profiles of male and female accountants are compared on the basis of the digital competences reported in the professional social network. Then, taking into account the competences held by the accountants, the next comparison is made in relation to their territorial macro-areas of belonging.

\subsection{Analysis of Information Technology Skills and Data Analytics Skills}

Table 2 summarizes the descriptive statistics of the final sample of the study, regarding the male/female ratio of the accountants registered on LinkedIn and the number of times the IT skills and data analytics skills are exposed in the LinkedIn profiles of male and female accountants.

As regards the composition of the sample, Table 2 shows a dominance of male profiles, with a share of $65.8 \%$, compared to a percentage of female accountants equal to $34.2 \%$ of the whole sample. This survey is in line with the overall statistics of LinkedIn users according to which, $57 \%$ of users are male, whereas $43 \%$ are female (Statista, 2020b). Therefore, the female profiles are slightly underrepresented compared to all those registered on LinkedIn. Nevertheless, it is worth pointing out that from the latest Gender Report of Italian body of Chartered Accountants, a difference emerges between the members of the Register (CNDCEC, 2020). As of January 1, 2019, there were 118,639 professionals, of whom only $32.8 \%$ were women, showing a slight decline compared to the share recorded on 1st January of the previous year, when the female presence was $33.8 \%$.

Another interesting picture emerges from the calculation of the frequency of occurrence (FOC) of IT skills and data analytics skills - exposed in LinkedIn profiles - according to gender. The analysis of the distribution of skills according to gender is necessary to understand how individual level variables could influence the possession of IT skills and data analytics skills. In detail, with regard to IT skills, an average FOC of 1.64 per LinkedIn user is identified. The Office package that includes Excel, Word and PowerPoint is the most frequently reported IT skill in the profiles of individual users, followed by the management of ERP software as "system application and product in data processing" (SAP) and the possession of skills in "structured query language" (SQL), in "visual basic for applications" (VBA) and in the use of "data warehousing" (DWH), as well as "customer relationship management" (CRM) systems and "Microsoft dynamics" software management (Note 6).

A completely different picture emerges from the observation of data analytics skills. An average FOC of 0.13 for each LinkedIn user shows that the data analytics skills are not widespread in the profiles of accountants. Specifically, among the data analytics skills found in LinkedIn profiles, "big data analytics" is the most frequently reported term, followed by "business analytics" and "business intelligence". According to Richins et al. (2017) big data and data analytics are terms that can be unified into "big data analytics" because data analytics techniques are necessary to analyse and to gather new information from big data that individually are not particularly relevant. Analysis tools and visualization software help users to find abnormal values and exceptions more easily. In addition, it facilitates not only the connection between data from different sources, but also the carrying out of increasingly advanced statistical analysis, using more sophisticated models and with more variables. According to Chen et al. (2012), other terms such as "business analytics" and "business intelligence" are used to describe the field that emerges, since the 1990s, around the trend of data analytics techniques. The terms "data science" and "predictive analytics" represent the methodologies to extract meaningful information and knowledge from big data (Provost \& Fawcett, 2013). In addition to these definitions, the terms "statistics", "data mining", "programming" and "modelling" describe the different activities of data preparation, data analysis and data application (Lorenz, Rüßmann, Strack, Lueth, \& Bolle, 2015).

Table 2 shows that in addition to the terms "big data analytics", "business analytics", "business intelligence", the skills visible in a greater number of profiles are "statistics", "data mining", "programming". The data analytics skills introduced more recently as "modelling", "data science" and "predictive analytics" are found only in a few profiles. 
Table 2. FOC of information technology skills and data analytics skills according to gender

\begin{tabular}{|c|c|c|c|c|c|c|}
\hline & \multicolumn{2}{|l|}{ Male } & \multicolumn{2}{|l|}{ Female } & \multicolumn{2}{|l|}{ Total } \\
\hline & $N$ & $(\%)$ & $N$ & $(\%)$ & $N$ & $(\%)$ \\
\hline \multicolumn{7}{|c|}{ Information technology skills } \\
\hline Office & 3,624 & 66.5 & 1,827 & 33.5 & 5,451 & 84.6 \\
\hline Excel & 2,915 & 67.2 & 1,420 & 32.8 & 4,335 & 67.3 \\
\hline SAP & 144 & 67.3 & 70 & 32.7 & 214 & 3.3 \\
\hline VBA & 47 & 67.1 & 23 & 32.9 & 70 & 1.1 \\
\hline SQL & 107 & 73.3 & 39 & 26.7 & 146 & 2.3 \\
\hline DWH & 38 & 76.0 & 12 & 24.0 & 50 & 0.8 \\
\hline ERP & 109 & 72.2 & 42 & 27.8 & 151 & 2.3 \\
\hline CRM & 63 & 63.6 & 36 & 36.4 & 99 & 1.5 \\
\hline Dynamics & 16 & 76.2 & 5 & 23.8 & 21 & 0.3 \\
\hline Total FOC & 7,063 & 67.0 & 3,474 & 33.0 & 10,537 & 163.6 \\
\hline Total study sample & 4,242 & 65.8 & 2,200 & 34.2 & 6,442 & 100.0 \\
\hline Average FOC & 1.67 & & 1.58 & & 1.64 & \\
\hline \multicolumn{7}{|l|}{ Data analytics skills } \\
\hline Business intelligence & 95 & 84.1 & 18 & 15.9 & 113 & 1.8 \\
\hline Statistics & 69 & 71.1 & 28 & 28.9 & 97 & 1.5 \\
\hline Programming & 36 & 70.6 & 15 & 29.4 & 51 & 0.8 \\
\hline Data mining & 47 & 61.0 & 30 & 39.0 & 77 & 1.2 \\
\hline Modelling & 13 & 46.4 & 15 & 53.6 & 28 & 0.4 \\
\hline Big data analytics & 170 & 66.1 & 87 & 33.9 & 257 & 4.0 \\
\hline Business analytics & 111 & 77.1 & 33 & 22.9 & 144 & 2.2 \\
\hline Predictive analytics & 13 & 68.4 & 6 & 31.6 & 19 & 0.3 \\
\hline Data science & 21 & 75.0 & 7 & 25.0 & 28 & 0.4 \\
\hline Total FOC & 575 & 70.6 & 239 & 29.4 & 814 & 12.6 \\
\hline Total study sample & 4,242 & 65.8 & 2,200 & 34.2 & 6,442 & 100.0 \\
\hline Average FOC & 0.14 & & 0.11 & & 0.13 & \\
\hline
\end{tabular}

Subsequently, from the observation of the total FOC on IT skills and data analytics skills in LinkedIn profiles according to gender, it is evident a gap between the profiles of male and female accountants (Figure 2). Despite the fact that $65.8 \%$ of the total study sample is male and $34.2 \%$ is female, the share of male users who reported data analytics skills in their LinkedIn profiles is $70.6 \%$ with an average FOC of 0,14 while for female users this figure is only $29.4 \%$. In relation to the possession of IT skills, the figures are more balanced, but show a similar trend. Male users, with a share of $67 \%$ and an average FOC of 1.67 , report the possession of IT skills while for female users this figure is $34.2 \%$.

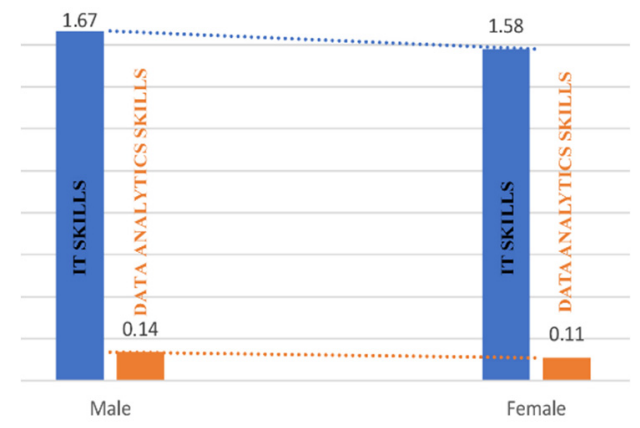

Figure 2. Average FOC on information technology skills e data analytics skills according to gender

Other interesting results emerge when looking at the distribution of IT skills and data analytics skills among LinkedIn users who belong to different Italian regions (Table 3). The analysis by territorial macro-areas shows how in northern Italy, the percentage of accountants reporting IT skills in their LinkedIn profile is higher $(47.6 \%)$ compared to the LinkedIn profiles of accountants belonging to the regions of the central (18.0\%) and the south Italy (34.4\%). A similar situation is found when looking at the distribution of data analytics skills, which, as 
previously seen, are little developed among LinkedIn users. In particular, the share of users who reported data analytics skills in their LinkedIn profiles is lower in southern Italy (19.7\%) compared to the northern accountants $(57.7 \%)$ and the central Italy $(22.6 \%)$. However, these results should be interpreted taking into account the sample distribution: $47.1 \%$ of the total sample of the study is located in northern Italy while only $17.9 \%$ and $35 \%$ in central and northern Italy, respectively. This composition is in line with the report of the Italian body "Consiglio Nazionale dei Dottori Commercialisti e degli Esperti Contabili" (CNDCEC, 2019). In 2018, there was a national growth trend among members of the Register of Dottori Commercialisti and Esperti Contabili, which, however, was not homogeneous at the territorial level. The gap between north and south, which had already emerged in previous years, was even more marked in 2018. In fact, as happened in 2017, the contribution to growth is almost entirely attributable to the north $(+370)$ and only, in a small part, to the central Italy $(+78)$, while the south Italy is in decline $(-142)$.

Table 3. FOC of information technology skills and data analytics skills according to macro-territorial areas

\begin{tabular}{lllllllll}
\hline & \multicolumn{2}{l}{ North Italy } & \multicolumn{2}{l}{ Central Italy } & \multicolumn{2}{l}{ South Italy } & \multicolumn{2}{l}{ Total } \\
& $N$ & $(\%)$ & $N$ & $(\%)$ & $N$ & $(\%)$ & $N$ & $(\%)$ \\
\hline Information technology skills & & & & & & & & \\
Office & & & & & & & & \\
Excel & 2,704 & 49.6 & 896 & 16.4 & 1,851 & 34.0 & 5,451 & 84.6 \\
SAP & 2,062 & 47.6 & 870 & 20.1 & 1,403 & 32.4 & 4,335 & 67.3 \\
VBA & 83 & 38.8 & 37 & 17.3 & 94 & 43.9 & 214 & 3.3 \\
SQL & 25 & 35.7 & 10 & 14.3 & 35 & 50.0 & 70 & 1.1 \\
DWH & 32 & 21.9 & 24 & 16.4 & 90 & 61.6 & 146 & 2.3 \\
ERP & 12 & 24.0 & 6 & 12.0 & 32 & 64.0 & 50 & 0.8 \\
CRM & 61 & 40.4 & 35 & 23.2 & 55 & 36.4 & 151 & 2.3 \\
Dynamics & 30 & 30.3 & 15 & 15.2 & 54 & 54.5 & 99 & 1.5 \\
Total FOC & 4 & 19.0 & 2 & 9.5 & 15 & 71.4 & 21 & 0.3 \\
Total study sample & 5,013 & 47.6 & 1,895 & 18.0 & 3,629 & 34.4 & 10,537 & 163.6 \\
Average FOC & 3,032 & 47.1 & 1,154 & 17.9 & 2,256 & 35.0 & 6,442 & 100.0 \\
\hline Data analytics skills & 1.65 & & 1.64 & & 1.61 & & 1.64 & \\
\hline Business intelligence & & & & & & & & 1.0 \\
Statistics & 77 & 68.1 & 15 & 13.3 & 21 & 18.6 & 113 \\
Programming & 52 & 53.6 & 27 & 27.8 & 18 & 18.6 & 97 & 1.5 \\
Data mining & 29 & 56.9 & 14 & 27.5 & 8 & 15.7 & 51 & 0.8 \\
Modelling & 41 & 53.2 & 12 & 15.6 & 24 & 31.2 & 77 & 1.2 \\
Big data analytics & 18 & 64.3 & 7 & 25.0 & 3 & 10.7 & 28 & 0.4 \\
Business analytics & 139 & 54.1 & 67 & 26.1 & 51 & 19.8 & 257 & 4.0 \\
Predictive analytics & 76 & 52.8 & 35 & 24.3 & 33 & 22.9 & 144 & 2.2 \\
Data science & 14 & 73.7 & 5 & 26.3 & 0 & 0.0 & 19 & 0.3 \\
FOC totale & 24 & 85.7 & 2 & 7.1 & 2 & 7.1 & 28 & 0.4 \\
Total study sample & 470 & 57.7 & 184 & 22.6 & 160 & 19.7 & 814 & 12.6 \\
Average FOC & 3,032 & 47.1 & 1,154 & 17.9 & 2,256 & 35.0 & 6,442 & 100.0 \\
\hline & 0.16 & & 0.16 & & 0.07 & & 0.13 & \\
\hline
\end{tabular}

Similar results emerge by analysing the FOC of IT skills and data analytics skills according to the region of each LinkedIn user. Figure 3 shows that in relation to IT skills, the LinkedIn profiles residing in the north show an average FOC higher (1.65) than accountants residing in the regions of the central (1.64) and of the south Italy (1.61). Looking at the distribution of data analytics skills, we find a similar situation, with average FOC lower among the accountants of the south (0.07) than those of the north and the center $(0.16)$. 


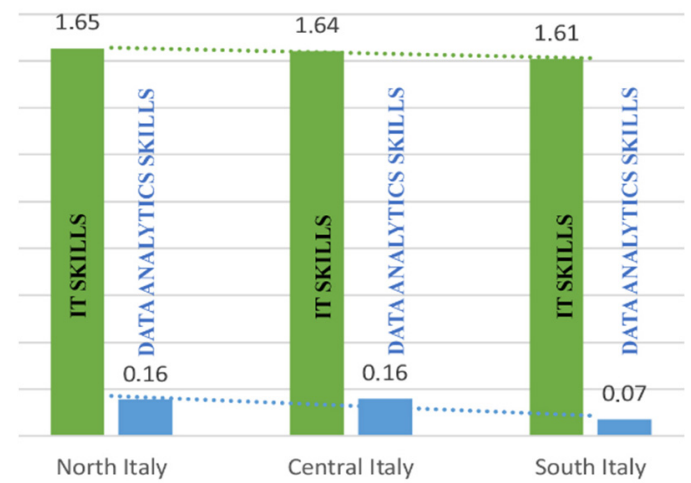

Figure 3. Average FOC of the information technology skills and data analytics skills according to macroterritorial areas

\section{Conclusion}

The purpose of this paper was to analyse the level of digitalization of Italian accountants (such as IT skills and data analytics skills) in order to investigate the type of digital competences and to what extent these competences are evident in their competence profiles.

The results, illustrated in the previous paragraph, show that there is a skills gap between male and female accountants. In particular, male users declare, more frequently, in their profiles, to possess digital skills than women accountants. It is useful to reiterate, however, that this does not necessarily imply that male accountants have, concretely, more technological skills than their female counterparts (Oesterreich \& Teuteberg 2019).

One possible explanation could be related to gender-related issues such as the lesser confidence that the woman has of herself compared to men (Gorbacheva et al. 2016). Another possible motivation would be found in the theory of impression management according to which individuals tend to conform to the cultural and social expectations associated with being a man or a woman. Guadagno and Cialdini (2007) point out that male individuals tend to self-value and self-promote by emphasizing their best features. The latter, therefore, could assume the same behavior in the context of social networks emphasizing too much their skill.

The study also highlighted the existence of a gap between the digital skills held by accountants who belong to different geographical areas. In fact, it has been noted that the accountants living in northern Italy have more digital skills than those living in central and southern Italy. However, the reason for this gap can be linked to the strong economic and technological imbalances that characterize the Italian regions (Evangelista, Iammarino, Mastrostefano, \& Silvani, 2002).

The results of this study have both theoretical and practical implications. The analysis showed a poor development of data analytics skills, which are reported only in $13 \%$ of LinkedIn profiles analysed. This shortage highlights the need for accounting professionals to invest more in their professional training by consolidating knowledge in the field of technology and digital innovation. Indeed, the professionalism and the know-how necessary to govern innovative technologies seems to be missing. It is appropriate to develop the right skills to manage technology innovation since no software will have the ability to replace the intuition and decision-making skills of the professional. Even today, the accountant is the only professional capable of playing the role of privileged interlocutor in the successful and effective use of innovative tools.

Therefore, accounting organisations should invest significantly in the digital training of professionals who, in most cases, are not yet prepared to lead companies in the innovation process. In addition, it would also be necessary to reduce "educational mismatch" by aligning university curricula with the digital and practical skills required by potential accountants (Mandrone, Pastore, \& Radicchia, 2015). According to Robinson (2010), it is essential to reform public education as "the current educational system has been thought and structured for a different age" with the consequence that the universities and other educational institutions "try to face the future by doing what they have done in the past". Hence, an aspiring accountant should acquire not only practical skills and professional and ethical values but also be aware of the importance of digital culture.

PwC (2019) also notes the need to renew educational and training courses in a digital perspective. The development of educational programs should therefore be oriented both to include tools and methodologies that transfer technical knowledge and develop soft skills, and to consolidate in individuals the awareness of the active role they 
can play in the knowledge society. This could be achieved by strengthening collaboration between the professional and academic worlds. In fact, cooperation would improve training programs and define more concrete research projects, based on the real needs of accountants (Lucianelli \& Citro, 2018).

Moreover, the differences found between male and female accountants compared to the level of digital skills expressed in their profiles, shows that female accountants tend to underestimate their skills compared to their male colleagues. This could explain the lack of success in women's working careers in terms of potential job offers and wage increases. Therefore, women should act with greater confidence by showing the skills that really characterize their professional profile. In addition, accounting organisations should specifically promote digital education for women.

This study has limitations which offer avenues for future research. First, the sample of data extracted is limited to the LinkedIn profiles of the Italian accountants only. This limitation prevents conclusions from being drawn on a larger scale. Therefore, in order to extend and validate the results of the study, it would be appropriate to develop further research observing the skills held by professionals from other geographical areas. A second limitation concerns the quality of the data examined. It was not possible to verify whether the professionals including in the data set actually possessed the skills presented on the professional social network. The risk is that users of online social networks may create self-presentations based on the desired image in an effort to control and influence the perception that others have of their image (Paliszkiewicz \& Mądra-Sawicka, 2016). However, the competence approval system, available on the professional network, should serve as a monitoring mechanism. Moreover, the information provided by LinkedIn members may be inaccurate or untrue. However, the data cleaning phase carried out precisely to exclude fake member profiles and profiles with no relevant content - ensures that a reliable set of profiles has been analysed. Indeed, if certain profiles, included in the sample examined, had been falsified, this would not have affected the results as their number would have been small. Despite these limitations, the analysed dataset can be considered reliable enough to acquire first information about the digital competences held by accountants in Italy.

\section{References}

Ahmed, A. (2003). The level of IT/IS skills in accounting programmes in British universities. Management Research News, 26(12), 20-58. https://doi.org/10.1108/01409170310783709

Aldredge, M., Rogers, C., \& Smith, J. (2020). The strategic transformation of accounting into a learned profession. Industry and Higher Education, 1-6. https://doi.org/10.1177/0950422220954319

Appelbaum, D., Kogan, A., \& Vasarhelyi, M. A. (2017). Big Data and analytics in the modern audit engagement: Research needs. Auditing: A Journal of Practice \& Theory, 36(4), 1-27. https://doi.org/10.2308/ajpt-51684

Bassellier, G., Benbasat, I., \& Reich, B. H. (2003). The Influence of Business Managers' IT Competence on Championing IT. Information Systems Research, 14(4), 317-336.

Bastian, M., Hayes, M., Vaughan, W., Shah, S., Skomoroch, P., \& Kim, H. (2014). LinkedIn skills: large-scale topic extraction and inference. Proceedings of the 8th ACM Conference on Recommender systems, 1-8.

Berger, T., \& Frey, B. (2016). Digitalisation, jobs and convergence in Europe: Strategies for closing the skills gap. Oxford: Oxford Martin School.

Bhimani, A., \& Willcocks, L. (2014). Digitisation, 'Big Data' and the transformation of accounting information. Accounting and Business Research, 44, 469-490. https://doi.org/10.1080/00014788.2014.910051

Bonsón, E., \& Bednárová, M. (2013). Corporate LinkedIn practices of Eurozone companies. Online Information Review, 37(6), 969-984. https://doi.org/10.1108/OIR-09-2012-0159

Boumans, J. W., \& Trilling, D. (2016). Taking stock of the toolkit: An overview of relevant automated content analysis approaches and techniques for digital journalism scholars. Digital Journalism, 4(1), 8-23. https://doi.org/10.1080/21670811.2015.1096598

Boyatzis, A. R. (1982). The Competent Manager: A Model for Effective Performance. New York: J. Wiley.

Braine, J. W. (2016). The need to bring finance and accounting into the digital age. Retrieved from https://www.cfoedge.com/blog/financial-leadership/the-need-to-bring-finance-accounting-into-the-digital-age/

Brynjolfsson, E., \& McAfee, A. (2014). The second machine age: Work, progress, and prosperity in a time of brilliant technologies. WW Norton \& Company.

Bullock, L. (2017). Accountants told to up their game on cyber security. Retrieved from https://www.accountantsdaily.com.au/technology/9953-mid-tier-warns-on-growing-cyber-threat 
Carnaghan, C. (2004). Discussion of IT Assurance Competencies. International Journal of Accounting Information Systems, 5, 67-273. https://doi.org/10.1016/j.accinf.2004.01.013

Chen, H., Chiang, R. H., \& Storey, V. C. (2012). Business intelligence and analytics: From Big Data to big impact. MIS Quarterly, 36(4), 1165-1188. https://doi.org/10.2307/41703503

Colquhoun, R. (2015). 11 tips on how to embrace technology in your business. Retrieved from https://www.intheblack.com/articles/2015/07/21/11-tips-on-how-to-embrace-technology-in-your-business

Consiglio Nazionale dei Dottori Commercialisti e degli Esperti Contabili (CNDCEC) (2020). Bilancio di genere del Consiglio Nazionale dei Dottori Commercialisti e degli Esperti Contabili. Retrieved from https://www.commercialisti.it/documents/20182/1236776/Allegato++Informativa+n.+772019.pdf/c3alafba-1df0-49b8-9c8a-f5aa779e916d

Consiglio Nazionale dei Dottori Commercialisti e degli Esperti Contabili (CNDCEC) (2019). Rapporto 2019 sull'Albo dei Dottori Commercialisti e degli Esperti Contabili. Retrieved from https://www.fondazionenazionalecommercialisti.it/node/1388

Crovara, M. (2009). Informazioni non strutturate. L'innovazione tecnologica e metodologica al servizio del mondo del lavoro, 51-62.

da Silva, R. J., Tommasetti, R., Gomes, M. Z., \& da Silva Macedo, M. A. (2020). Accountants' IT responsibilities and competencies from a student perspective. Higher Education, Skills and Work-Based Learning, 2042-3896. https://doi.org/10.1108/HESWBL-02-2020-0028

Damasiotis, V., Trivellas, P., Santouridis, I., Nikolopoulos, S. \& Tsifora, E., (2015). IT competences for professional accountants. A review. Procedia-Social and Behavioral Sciences, 175, 537-545. https://doi.org/10.1016/j.sbspro.2015.01.1234

European Commission. (2020). Digital economy and society index (DESI) 2020. Thematic chapters. 1-124. Retrieved from https://ec.europa.eu/digital-single-market/en/news/digital-economy-and-society-index-desi-2020

Evangelista, R., Iammarino, S., Mastrostefano, V., \& Silvani, A. (2002). Looking for regional systems of innovation: evidence from the Italian innovation survey. Regional studies, 36(2), 173-186. https://doi.org/10.1080/00343400220121963

Ford, M. (2015). Rise of the Robots: Technology and the Threat of a Jobless Future. Basic Books.

Frey, C. B., \& Osborne, M. A. (2017). The future of employment: how susceptible are jobs to computerisation? Technological forecasting and social change, 114, 254-280. https://doi.org/10.1016/j.techfore.2016.08.019

Gandomi, A., \& Haider, M. (2015). Beyond the hype: Big data concepts, methods, and analytics. International Journal of Information Management, 35(2), 137-144. https://doi.org/10.1016/j.ijinfomgt.2014.10.007

Georgieva, D. (2019). Digital competences of accountants within the context of the fourth industrial revolution. Икономика, 21, 10(2), 34-58.

Gorbacheva, E., Stein, A., Schmiedel, T., \& Müller, O. (2016). The role of gender in business process management competence supply. Business \& Information Systems Engineering, 58(3), 213-231. https://doi.org/10.1007/s12599-016-0428-2

Guadagno, R. E., \& Cialdini, R. B. (2007). Gender differences in impression management in organizations: a qualitative review. Sex Roles, 56(7/8), 483-494. https://doi.org/10.1007/s11199-007-9187-3

Heagy, C. D., \& Gallum, R. A. (1994). Recommended microcomputer knowledge for accounting graduates: A survey. Journal of Accounting Education, 12(3), 205-210. https://doi.org/10.1016/0748-5751(94)90032-9

Hutchinson A. (2020). LinkedIn Reaches 675 Million Members, Continues to See 'Record Levels of Engagement. Retrieved from https://www.socialmediatoday.com/news/linkedin-reaches-675-million- members-continuesto-see-record-levels-of-en/571435/

International Federation of Accountants (IFAC). (2017). Handbook of international education pronouncements. Retrieved from https://www.ifac.org/publications-resources/2017- handbook-international-educationpronouncements- 8 .

International Federation of Accountants, Education Committee (IFAC Education Committee). (2003). International Education Guideline 11: Information Technology for Professional Accountants. New York: IFAC.

Jordan J. (2013). The risks of Big Data for companies. Wall Street Journal. Retrieved from 
http://www.wsj.com/articles/SB10001424052702304526204579102941708296708

Jordan, A. S. (1999). The impact technology is having on the accounting profession. Journal of Accounting Education, 2(17), 341-348.

Kaye, G. R., \& Nicholson, A. H. (1992). An educational framework for information technology in accounting and management education. Computers \& Education, 19(1-2), 105-112. https://doi.org/10.1016/03601315(92)90016-X

Larres Mc Court, P., \& Oyelere, P. (1999). A critical analysis of self-assessed entry level personal computer skills among newly-qualifies Irish chartered accountants. Accounting Education, 8(3), 203-216. https://doi.org/10.1080/096392899330892

Leopold, E., \& Kindermann, J. (2002). Text categorization with support vector machines. How to represent texts in input space? Machine Learning, 46(1), 423-444. https://doi.org/10.1023/A:1012491419635

Lohmann, P., \& Zur Muehlen, M. (2015). Business Process management skills and roles: an investigation of the demand and supply side of BPM professionals. In H. Motahari-Nezhad, J. Recker e M. Weidlich (Eds.), Business Process Management (pp. 317-332). Cham: Springer.

Lorenz, M., Rüßmann, M., Strack, R., Lueth, K. L., \& Bolle, M. (2015). Man and machine in industry 4.0: How will technology transform the industrial workforce through 2025. The Boston Consulting Group, 2.

Lucianelli, G., \& Citro, F. (2018). Accounting Education for Professional Accountants: Evidence from Italy. International Journal of Business and Management, 13(8), 1-15. https://doi.org/10.5539/ijbm.v13n8p1

Maisurah, K., Bahador, K., \& Haider, A. (2012). Information Technology Skills and Competencies - A Case for Professional Accountants. BIS (Workshops) LNBIP, 127, 81-87.

Mandrone, E., Pastore, F., \& Radicchia, D. (2015). Educational mismatch: new empirical evidence from the ISFOL PLUS data. Novara: Aiel.

Manyika, J., Lund, S., Chui, M., Bughin, J., Woetzel, J., Batra, P., Ko, R., \& Sanghvi, S. (2017). Jobs lost, jobs gained: what the future of work will mean for jobs, skills, and wages. McKinsey Global Institute. Retrieved from https://www.mckinsey.com/featured-insights/future-of-work/jobs-lost-jobs-gained-what-the-future-ofwork-will-mean-for-jobs-skills-and-wages\#

Oesterreich, T. D., \& Teuteberg, F. (2019). The role of business analytics in the controllers and management accountants' competence profiles. Journal of Accounting \& Organizational Change, 15(2), 330-356. https://doi.org/10.1108/JAOC-10-2018-0097

Paliszkiewicz, J. \& Mądra-Sawicka, M. (2016), Impression management in social media: the example of LinkedIn. Management (18544223), 11(3), 203-212.

Pan, G., \& Seow, P. S. (2016). Preparing accounting graduates for digital revolution: A critical review of information technology competencies and skills development. Journal of Education for Business, 91(3), 166175. https://doi.org/10.1080/08832323.2016.1145622

Provost, F., \& Fawcett, T. (2013). Data science and its relationship to big data and data-driven decision making. Big Data, 1(1), 51-59. https://doi.org/10.1089/big.2013.1508

PwC (2019). Digital Skills. Come ripensare l'istruzione e la formazione nell'era digitale: competenze digitali e nuovi modelli per l'apprendimento. Retrieved from https://www.pwc.com/it/it/publications/assets/docs/PwC Ufficio_Studi_Digital_Skills.pdf.

Richins, G., Stapleton, A., Stratopoulos, T.C., \& Wong, C. (2017). Big data analytics: Opportunity or threat for the accounting profession? Journal of Information Systems, 31(3), 63-79. https://doi.org/10.2308/isys-51805

Riddell, C. (2016). Digital disruption transforming the finance sector. Retrieved from https://www.acuitymag.com/opinion/digital-disruption-transforming-the-finance-sector

Roberts, M. E., Stewart, B. M., Tingley, D., Lucas, C., Leder-Luis, J., Gadarian, S. K., \& Rand, D. G. (2014). Structural topic models for open-ended survey responses. American Journal of Political Science, 58(4), 10641082. https://doi.org/10.1111/ajps.12103

Robinson, K. (2010). Changing Education Paradigms, RSA Animate, RSA Animate, The Royal Society of Arts, London. Retrieved from https://www.ted.com/talks/ken_robinson_changing_education_paradigms.

Schneider, G. P., Dai, J., Janvrin, D. J., Ajayi, K., \& Raschke, R. L. (2015). Infer, predict, and assure: Accounting opportunities in data analytics. Accounting Horizons, 29(3), 719-742. https://doi.org/10.2308/acch-51140 
Sievers, K., Wodzicki, K., Aberle, I., Keckeisen, M., \& Cress, U. (2015). Self-presentation in professional networks: More than just window dressing. Computers in Human Behavior, 50, 25-30. https://doi.org/10.1016/j.chb.2015.03.046

Spencer, L. M., \& Spencer, S. M. (1993). Competency at Work: Models for Superior Performance. New York: John Wiley and Sons.

Statista (2020a). Social network market share held by LinkedIn monthly in Italy from January 2017 to May 2020. Retrieved from https:/www.statista.com/statistics/622889/linkedin-social-network-market-share-in-italy/

Statista (2020b). Distribution of LinkedIn users worldwide as of July 2020, by gender. Retrieved from https://www.statista.com/statistics/933964/distribution-of-users-on-linkedin-worldwide-gender/

Stone, D. N., Arunachalam, V., \& Chandler, J. S. (1996). Cross-Cultural Comparisons: An Empirical Investigation of Knowledge, Skills, Self-Efficacy and Computer Anxiety in Accounting Education. Issues in Accounting Education, 11(2), 345-376.

Susskind, R., \& Susskind, D. (2015). The Future of the Professions: How Technology Will Transform the Work of Human Experts. Oxford University Press.

Warren Jr, J. D., Moffitt, K. C., \& Byrnes, P. (2015). How Big Data will change accounting. Accounting Horizons, 29(2), 397-407. https://doi.org/10.2308/acch-51069

Welbers, K., Van Atteveldt, W., \& Benoit, K. (2017). Text analysis in R. Communication Methods and Measures, 11(4), 245-265. https://doi.org/10.1080/19312458.2017.1387238

Wessels, P. L. (2005). Critical information and communication technology (ICT) skills for professional accountants. Meditari Accountancy Research, 13(1), 87-103. https://doi.org/10.1108/10222529200500006

Zhyvets, A. (2018). Evolution of professional competencies of accountants of small enterprises in the digital economy of Ukraine. Baltic Journal of Economic Studies, 4(5), 87-93. https://doi.org/10.30525/22560742/2018-4-5-87-93

\section{Notes}

Note 1. The Artificial intelligence specialist is the one who guides the process of application and detection of algorithms of Artificial Intelligence, supervises the activities of "training" of algorithms and identifies qualitative metrics for the evaluation of the accuracy achieved. The Big data specialist is the one who guides the process of identification and application of technological architectures aimed at the management of structured and unstructured data. It also defines the requirements and strategies to extract the value needed by the organization's business.

Note 2. The Cloud computing is defined as a model that allows a useful and on-demand access to the system to share a pool of resources that can be quickly provided and downloaded with an insignificant administrative effort or a specialized cooperative collaboration.

Note 3. The Enterprise Resource Planning is a management system that integrates and automates all business processes in the sales and distribution, manufacturing, logistics, invoicing and human resources sectors. It ensures a continuous flow between the different areas or departments of the company avoiding that the organization is divided into watertight compartments. The Extensible Business Reporting Language is an electronic language. It belongs to the XML family which consists of digital labeling of financial and non-financial accounting data and information. The creation of the XBRL allows to avoid the (re)typing of the data by making more fast the production, the analysis and the transmission of the information that compose the business reporting. The Business Intelligence is an integrated system of processes and technologies that collect, coordinate and analyse a huge amount of data. In many cases, the data analysed by the BI system are generated by an ERP system, in fact, often the BI system is considered an extension of the latter. The Business Analytics represents a key analytical component of business intelligence that integrates data management activity through data warehousing and data mining systems with visualization, descriptive and predictive modeling, text analysis and statistical analysis. This facilitates the exploratory and iterative process of past business performance which, in turn, allows to obtain information necessary for business planning

Note 4. The Machine learning applications include a range of statistical techniques such as mathematical modeling, data visualization, and model recognition, which use a probabilistic framework to deduce models that explain 
observed data. The Natural language processing focuses on understanding unstructured data such as text mining, manual text analysis and readability analysis.

Note 5. The Data warehousing is a technology that collects a collection of structured data for the purpose of conducting analyses aimed at the implementation of decision-making processes and the improvement of information assets. A data warehouse is in fact typically designed and developed as an information collector that integrates and reorganizes data from various sources and makes them available for analysis and evaluation. The Data mining is the analysis of large data sets to represent a real problem and develop a systematic and robust approach to regenerate the problem with different inputs or find out how certain aspects are related to each other.

Note 6. The Office package includes software applications that automate a range of tasks. In particular, it contains various programs such as Excel that allows you to create spreadsheets and tables; Word that is used to create different text documents and PowerPoint which allows the creation of multimedia presentations. The SAP system is a management software that allows you to better manage the different business areas such as accounting, administration, logistics, sales, production, management control and human resources. It creates a function or process model that reflects the enterprise allowing total control and, consequently, increasing efficiency. The $S Q L$ language has an articulate structure. It contains other languages through which it is possible to perform various actions, such as to find information from the database by querying the stored data; to act directly on the database schema creating and modifying the individual objects that compose it; to read and to edit but also to delete the data contained in the database and to extract information from the database interrogating it through the formulation of specific "queries", or programming constructs. The VBA is a programming language that Microsoft has created to allow the experienced user to perform routines within the Microsoft Office work environment. It differs from Visual Basic because the latter is an object language created by Microsoft in the early 90's for the creation of programs for older versions of Windows while the VBA is a language with which you realize procedures that are used inside the Office package. For the definition of $D W H$, see note 5. The CRM system represents a software that manages the relationships between the professional and the enterprises customers. It allows to consolidate the interaction with the customer through the creation of special databases containing all the detailed information. Therefore, the professional can access, quickly and from any place, the data of all its customers. The Microsoft dynamics software is prevalent among small and medium-sized enterprises (SMEs). The ease of use of the software packages that compose it ensures the achievement of maximum efficiency and interfunctional integration by creating links between the various elements of the information structure. The software architecture, in this way, facilitates the flow of information between all functions within the company such as manufacturing, logistics, finance and human resources.

\section{Copyrights}

Copyright for this article is retained by the author(s), with first publication rights granted to the journal.

This is an open-access article distributed under the terms and conditions of the Creative Commons Attribution license (http://creativecommons.org/licenses/by/4.0/). 